\title{
IMPACT OF STREET CANYON GEOMETRY ON OUTDOOR THERMAL COMFORT AND WEATHER PARAMETERS IN PÉCS
}

\author{
${ }^{1}$ Mohammad S. ALBDOUR, ${ }^{2}$ Bálint BARANYAI* \\ ${ }^{1}$ Marcel Breuer Doctoral School, Faculty of Engineering and Information Technology \\ University of Pecs, Boszorkany u. 2, 7624 Pecs, Hungary, e-mail: albdour_m@yahoo.com \\ ${ }^{2}$ Department of Building Structures and Energy Design, Institute of Architecture \\ Faculty of Engineering and Information Technology, Boszorkány u. 2 \\ and János Szentágothai Research Center, Ifjúság u. 20, University of Pécs \\ H-7624 Pécs, Hungary, e-mail: balint.baranyai@mik.pte.hu
}

Received 26 December 2018; accepted 25 March 2019

\begin{abstract}
As streets cover almost twenty-five percentages of the urban open spaces, designing streets is a vital issue in creating thermal comfort for urban environmental design. The geometry of the street (height/width ratio) as well as orientation directly influences the airspeed, solar access in urban canyon and as a result thermal comfort at the pedestrian level. This study examined the street geometry case study's scenarios with different street geometries and investigates its effects on outdoor thermal comfort as well as the weather parameters. However, according to the matrix assessment conducted by the author, the vast street canyons (height/width $=0.65 \mathrm{~m} / 14.5 \mathrm{~m}$ with an orientation parallel to the prevailing wind direction achieved the best results. Nevertheless, the aim of this paper is to investigate the impact of street canyon geometry on outdoor thermal comfort and its parameters in the summertime using numerical modeling.
\end{abstract}

Keywords: Urban area, Street canyon geometry, Outdoor thermal comfort, CFD tool

\section{Introduction}

The energy demand of the built environment is almost $50 \%$ of the total energy demand of a national economy [1]. In order to provide a pleasant microclimate in urban areas, designing urban streets in a way which brings about appropriate airflow and utilize solar access is vital and essential. This could affect the global climate and energy consumption of buildings. The microclimate of urban open spaces is influenced by several parameters like the urban form and geometry, urban density, the vegetation, the

${ }^{*}$ Corresponding Author 
water levels and the properties of surfaces. As more than a quarter of the urban areas are usually covered by streets, designing urban streets plays an important role in creating the urban climate. The urban streets vary in geometry as defined by height/width ratio $(\mathrm{H} / \mathrm{W})$ and length/width $(\mathrm{L} / \mathrm{W})$ and also the orientation that is defined by its long axis. These parameters directly influence the absorption and emission of solar radiation and also urban ventilation, which have a significant impact on the temperature variations within the street as well as the surrounding environment [2], [3]. The Urban Street Canyon (UC), which is a simplified rectangular vertical profile of infinite length, has been widely adopted in urban climate research as the basic structural unit [4].

\section{Street wind orientation}

The performance of each urban form, in relation to natural ventilation, greatly depends on the orientation of the streets' grid and the buildings that line them on both sides. Street orientation could be parallel, oblique or perpendicular to the wind direction. When the major streets in a site are oriented parallel to the prevailing wind, the highest velocity could be obtained in the streets and the adjacent open spaces. Generally speaking, the optimal street orientation for ventilation purposes, which is advised by Givoni [5], [6], was found to be oblique to wind direction by approximately $20-30^{\circ}$ (see Fig. 1) with the narrowest buildings' façades facing the wind [5]. However, the real street orientation in the case study is almost $5^{\circ}$ which means within the optimum street orientation range for natural ventilation as well as outdoor thermal comfort.

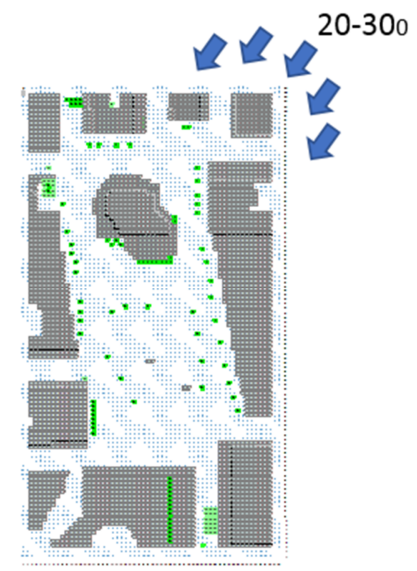

Fig. 1. The optimum street orientation for natural ventilation and outdoor thermal comfort

\section{Street canyon configurations}

The street canyon can be defined as 'the space between buildings lining up along both sides of a street, from street surface to rooftop level'. Street canyon geometry is 
also one of the main measures that can have a great impact on air temperature distribution within the street. This in turn could affect pedestrian thermal comfort [5]. The geometry of a street canyon is expressed by its 'aspect ratio' including the ratio of the height of the building to the width of the street. If the canyon has an aspect ratio of around equal to 1 with no major openings on the walls it is called a uniform street canyon. A canyon with an aspect ratio below 0.5 is a shallow street canyon; and the aspect ratio of 2 , represents a deep street canyon. The length of canyon illustrates the road distance between two main intersections subdividing the street canyon into short $(\mathrm{L} / \mathrm{H}=3)$, medium $(\mathrm{L} / \mathrm{H}=5)$ and long $(\mathrm{L} / \mathrm{H}=7)$. It has been proved that the geometry and orientation of the street canyon affect outdoor and indoor environments, solar access inside and outside the buildings, the permeability to airflow for urban ventilation, as well as the potential for cooling of the whole urban system. Therefore, the street design influences the thermal comfort at the pedestrian level as well as the global energy consumption of urban buildings [2].

\section{Methodology}

The importance of new green branches of science aiming to find solutions to environmental challenges has been internationally considered as undisputable [7]. Numerical simulations using ENVI-met code were applied due to its high capabilities and few data entries. The program uses a three-dimensional computational fluid dynamics and energy balance model; the simulation study can analyze unlimited number of points in the model. It is used to simulate the impact of certain urban design strategies on thermal comfort at a certain location [8]. Nonetheless, the study is limited to the moderately warm-wet climate of Pecs. Although some of the findings may be generalized, the conclusions of the study are not necessarily valid throughout moderately warm-wet climate groups, since there are climatic and considerable variations between different cities in terms of size, planning principles, proximity to the sea, and topography, etc. Moreover, visual and acoustical comfort performance is not investigated here. Moreover, due to the diverse scenarios and meteorological conditions, the field measurements could not give the total conclusion. In contrast, the Computational Fluid Dynamics (CFD) simulation method plays an important role in the research because of its means of modeling simplified and optimized. However, the methodology will be divided into four sections first one is describing the selected study site, second analyzing the street canyons of the chosen case, and summarizing the street canyon of the case study features, third, applying the ENVI-met software to simulate the urban microclimate with different street canyon geometries. Nevertheless, fourth section discusses the simulated results as well as draws the related conclusion.

\subsection{Selected study overview}

The square is located in the heart of the old town of Pécs, on the southern side of the Mecsek Mountain. Twelve streets run into the square, starting from the south clockwise: Irgalmasok street, Jókai square, Ferencesek street, Ciszterci alley, Janus Pannonius 
street, Szepessy Ignác street, Hunyadi János street, Megye street, Mária street, Király street, Perczel Miklós street and Munkácsy Mihály street [9] (Fig. 2).

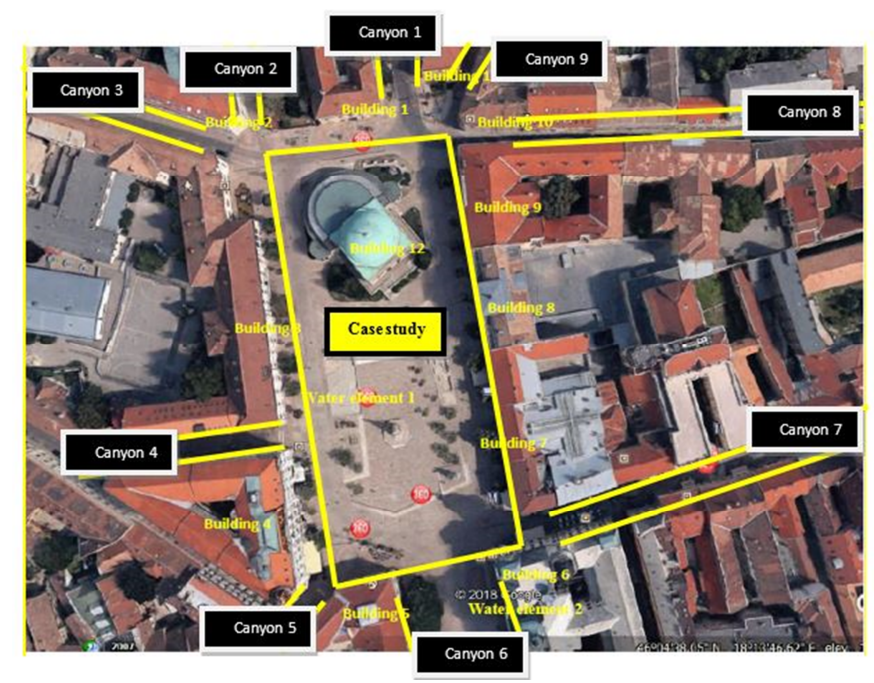

Fig. 2. The case study's master plan [10]

\subsection{Street canyons}

Analyzing the street geometrical configurations of the case study site showed that street width ranges from $6 \mathrm{~m}$ to $36 \mathrm{~m}$ with the majority of streets almost more than $40 \%$ having a width of $10 \mathrm{~m}$ (Table I). The other widths can be found in the site only one or two times maximum. The ratio between height and width was found to be (1.1-1.3) in most cases so more the $60 \%$ (Table I), in other words, six cases out of nine. The H/W in the site ranges from 0.3 to 1.75 and the median around 1.1. According to the canyon classification mentioned in street canyon configurations and from the site analysis stated above, so it can be reported that the most common canyon configuration across the site is a deep canyon. Also, it can be seen that all canyons within the site are short canyons.

\section{Table I}

Street canyon heights, widths and height/width ratios across the case study's site

\begin{tabular}{|l|l|l|l|}
\hline Canyon street No & Height & Width & H/W \\
\hline Canyon one & 8 & 14.5 & 0.55 \\
Canyon two & 10 & 7.5 & 1.3 \\
Canyon three & 12 & 10.5 & 1.2 \\
Canyon four & 14 & 8 & 1.75 \\
Canyon five & 10 & 9 & 1.1 \\
Canyon six & 10 & 36 & 0.3 \\
Canyon seven & 13 & 11 & 1.2 \\
Canyon eight & 10 & 7.5 & 1.3 \\
Canyon nine & 7 & 6 & 1.2 \\
\hline
\end{tabular}

Pollack Periodica 14, 2019, 3 
Street width ranges between $5.5 \mathrm{~m}$ and $36 \mathrm{~m}$ with the majority of streets $(33.7 \%)$ having a width of $10 \mathrm{~m}$ (Fig. 3). The other widths can be found in the site only once or twice with an existence percentage of $1.05 \%$ and $8.42 \%$ respectively. According to this analysis and considering $\mathrm{H}=19 \mathrm{~m}$ (The block's height), the H/W of the site ranges from 3.45 to 0.25 with the majority of them having $\mathrm{H} / \mathrm{W}=1.9$ (Fig. 3). The most prevailing H/W ratios of the case study's master plan will be modeled (Table II).

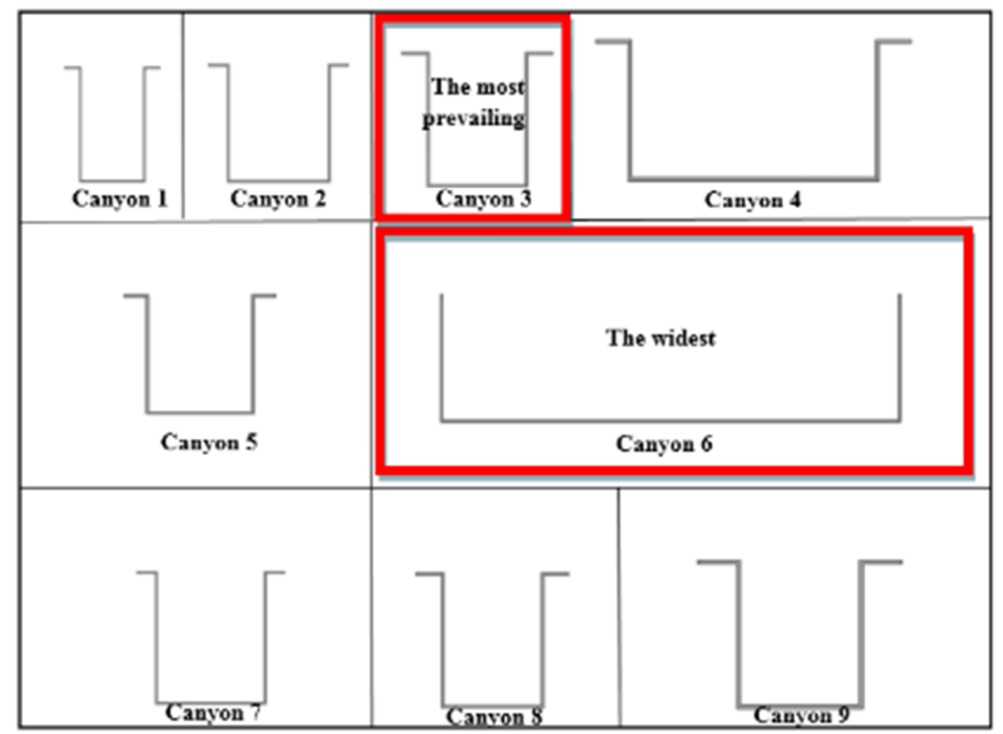

Fig. 3. Street canyon profile across the case study's site

Table II

The most prevailing H/W ratios of the case study's master plan

\begin{tabular}{|l|l|}
\hline Canyon geometry & $\mathrm{H} / \mathrm{W}=0.65$ \\
& $\mathrm{H} / \mathrm{W}=1$ \\
$\mathrm{H} / \mathrm{W}=1.5$
\end{tabular}

\subsection{Summary in regard to street canyon geometry}

The results of the case study analysis could be briefly concluded as follows:

- The site is flat with no slopes nor any nearby heat sinks;

- The master plan is surrounded by 11 blocks and one in the middle;

- Streets that were found to be oriented to the north east - south west direction and north west - south east direction mostly;

- The most common canyon configurations within the site were found to be deep short canyons with a width of $6 \mathrm{~m}, \mathrm{H} / \mathrm{W}$ ratio $=1.2$. 


\section{Results and discussion}

The urban outdoor thermal comfort in this study was performed by examining the relationship between the ratios of the building heights to street widths. Three scenarios with different street geometries were chosen; $\mathrm{H} / \mathrm{W}=0.65, \mathrm{H} / \mathrm{W}=1, \mathrm{H} / \mathrm{W}=1.5$ (see Fig. 4).
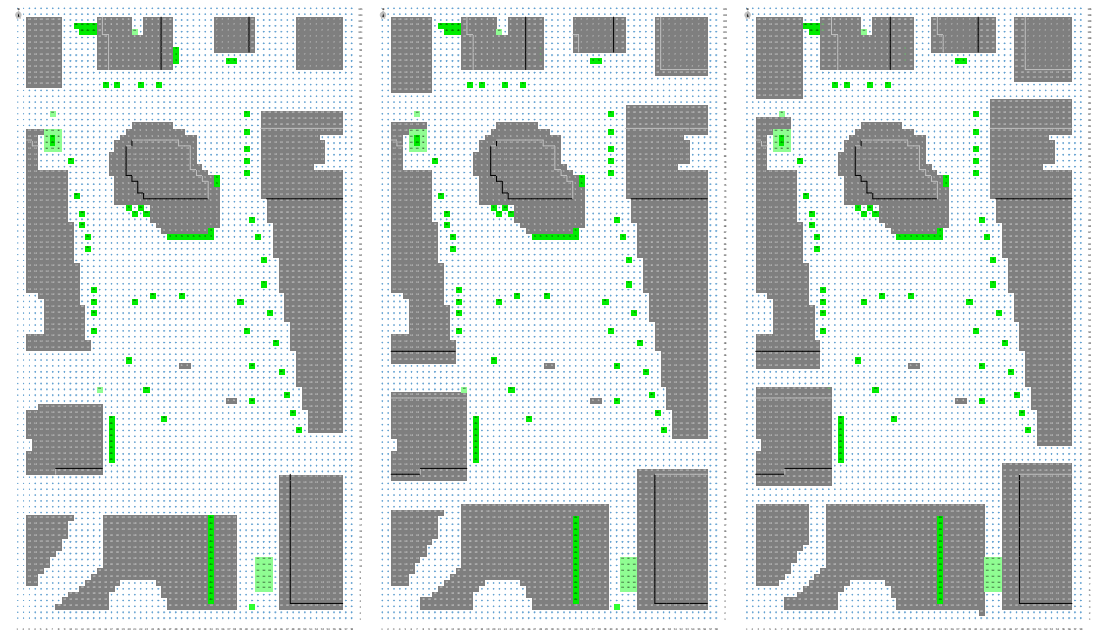

Fig. 4. The chosen scenarios of the case study's master plan, $\mathrm{H} / \mathrm{W}=1.5 ; \mathrm{H} / \mathrm{W}=1 ; \mathrm{H} / \mathrm{W}=0.65$, respectively from left to right

In order to assess the whole site, thermal performance simulations were conducted at 14:00 PM on the 21st of July as a representation for the summer period. It is an extreme summer day analyzed by climate consultant 6.0 [11].

When the street orientation is constant, the effect of canyon geometry on outdoor thermal comfort could be measured. However, the air temperature (Ta), relative humidity (RH), airspeed (WS), Predicted mean vote (PMV), Mean Radiant Temperature (MRT), Carbon dioxide $\left(\mathrm{CO}_{2}\right)$ were averaged over the square (Fig. 5), it can be clearly seen that:

- $\quad$ On average the air temperature is $304 \mathrm{~K}$ (hot);

- The average relative humidity is $35.3 \%$ (comfort);

- On average wind speed is $1.55 \mathrm{~m} / \mathrm{s}$ (light breeze);

- The mean PMV value 5.1 (very hot);

- The total average mean radiant temperature is $353 \mathrm{~K}$;

- The mean $\mathrm{CO}_{2}$ is 358 PPM (normal range).

High airspeed has been noticed in the cases' inner street canyons, as most of the streets are parallel to the prevailing wind direction which allowed a more substantial amount of wind to pass through the streets with high-speed values. 
The following simulation maps show that the air temperature, relative humidity, wind speed, predicted mean vote, mean radiant temperature as well as $\mathrm{CO}_{2}$ on the day $21^{\text {th }}$ of July 2018 . The results have revealed that (Fig. 6);

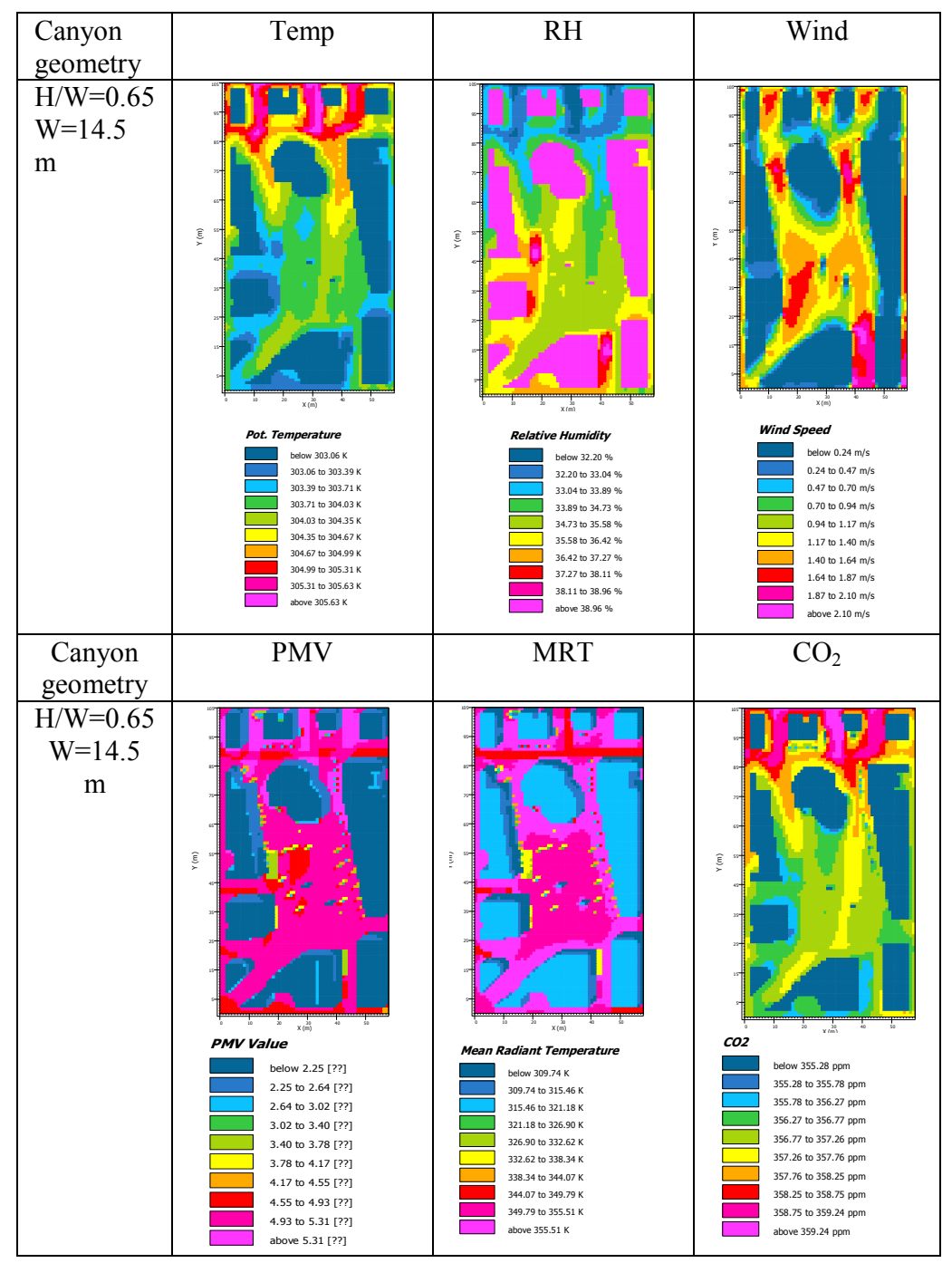

Fig. 5. The simulated PMV and weather parameters in the first scenario

- On average the air temperature is $304.3 \mathrm{~K}$ (hot), with $0.3 \mathrm{~K}$ higher than the first scenario;

- The mean relative humidity is $34.4 \%$ (within the comfort range), with $0.9 \%$ lower than the first scenario; 
- The average wind speed is $1.4 \mathrm{~m} / \mathrm{s}$ (light breeze), with $0.15 \mathrm{~m} / \mathrm{s}$ less than the first scenario;

- The mean PMV value 5 (very hot), with 0.1 higher than the first scenario, very slight improvement;

- The average mean radiant temperature is $353 \mathrm{~K}$, very identical to the first case;

- On average $\mathrm{CO}_{2}$ is 358 PPM (normal range), similar to the first case.

\begin{tabular}{|l|c|c|c|c|}
\hline \multicolumn{1}{|c|}{$\begin{array}{l}\text { Canyon } \\
\text { geometry }\end{array}$} & Temp & & RH \\
\hline $\mathrm{H} / \mathrm{W} 1$ \\
$\mathrm{~W}=10 \mathrm{~m}$
\end{tabular}

Fig. 6. The simulated PMV and weather parameters in the second scenario 
The results of the third scenario (Fig. 7) have been analyzed and some general conclusions could be drawn as follows:

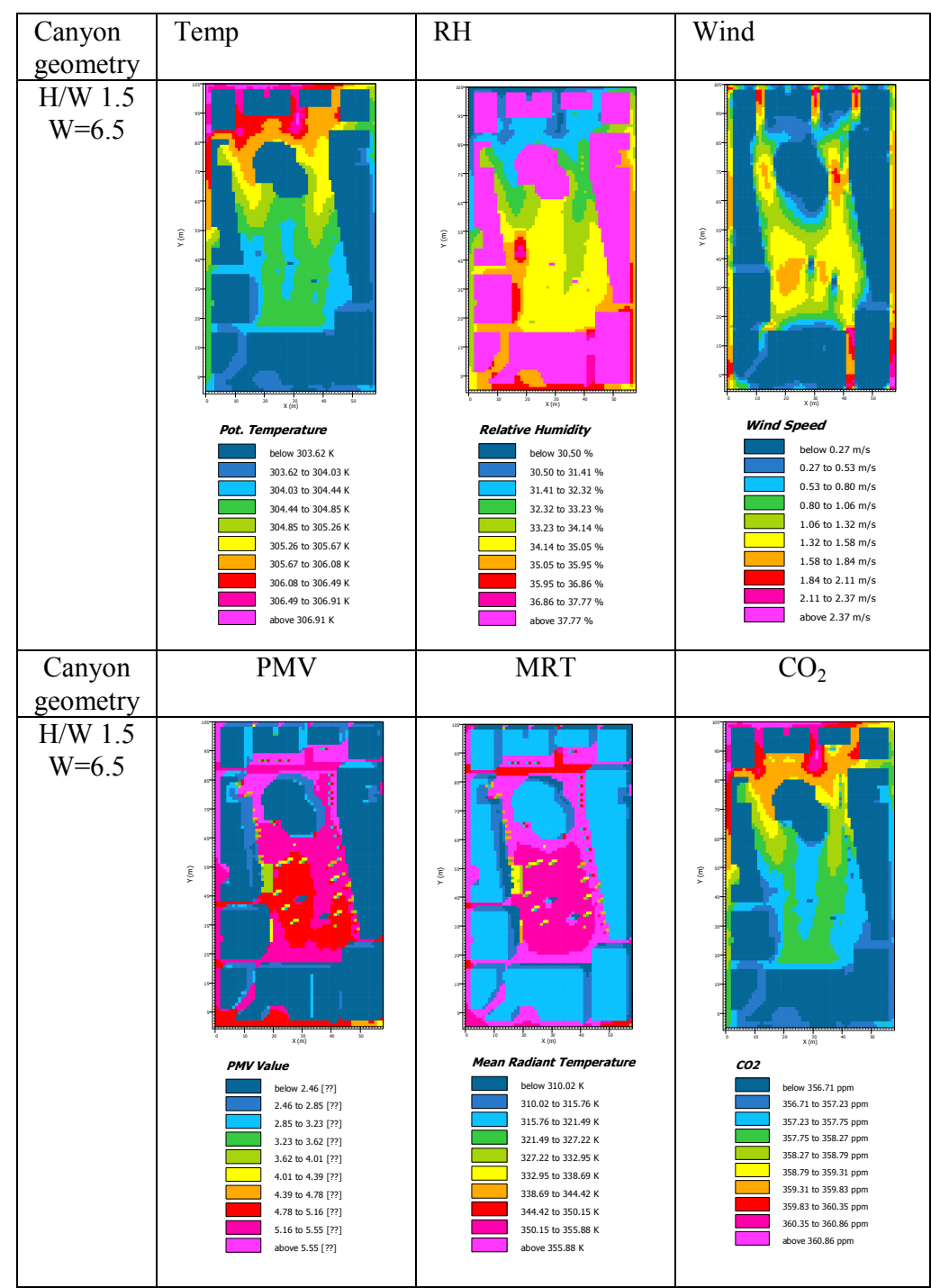

Fig. 7. The simulated PMV and weather parameters in the third scenario

- On average the temperature $(\mathrm{K})$ is $305.2 \mathrm{~K}$, with $1.2 \mathrm{~K}$ higher than the first case;

- The mean relative humidity is $34 \%$;

- The average airspeed is $1.34 \mathrm{~m} / \mathrm{s}$ (light breeze), with $1.3 \%$ lower than the first scenario; 
- On average the PMV value 5.1 (very hot), almost constant in all scenarios;

- The average of mean radiant temperature is $353 \mathrm{~K}$, constant in all scenarios;

- The mean $\mathrm{CO}_{2}$ is 358 PPM (normal range), constant in all scenarios.

The simulated H/W ratios are displayed in (Table III), suggesting that a lower H/W ratio (indicating a wider street width), a higher $\mathrm{H} / \mathrm{W}$ ratio (signifying an overtly narrow street width). Nevertheless, there is a minor difference between the three cases with the first case $(\mathrm{H} / \mathrm{W}=0.65)$ reaching the lowest temperature and the highest airspeed since street width of $(W=14.5 \mathrm{~m})$ induced natural ventilation.

It can be noticed that the scenario number one has reached the highest enhancement in the public square. However, the case has been selected as the optimum scenario.

- The first scenario achieved the lowest mean air temperature among the three scenarios $(304 \mathrm{~K})$, with $1.2 \mathrm{~K}$ lower than the third scenario that as a result of high wind speed and better ventilation;

- The first scenario archived the highest relative humidity among the set scenarios $35.3 \%$, with $1.3 \%$ higher than the third scenario that because of proper ventilation and a larger amount of air passes through the canyons;

- The first scenario achieved the highest wind speed of $1.55 \mathrm{~m} / \mathrm{s}$ on average due to wide streets;

- The second scenario achieved the lowest PMV value on average 5;

- MRT is constant in all scenarios;

- $\mathrm{CO}_{2}$ is almost constant in all scenarios.

Table III

The matrix assessment of the average of PMV and weather parameters

\begin{tabular}{|c|c|c|c|c|c|c|}
\hline $\begin{array}{c}\text { Street } \\
\text { canyon } \\
\text { geometry }\end{array}$ & $\begin{array}{c}\text { Temperature } \\
(\mathrm{K})\end{array}$ & $\begin{array}{c}\text { Relative } \\
\text { Humidity } \\
(\%)\end{array}$ & $\begin{array}{c}\text { Wind } \\
\text { speed } \\
(\mathrm{m} / \mathrm{s})\end{array}$ & $\begin{array}{c}\text { PMV } \\
\text { value }\end{array}$ & $\begin{array}{c}\text { Mean radiant } \\
\text { temperature }(\mathrm{K})\end{array}$ & $\begin{array}{c}\mathrm{CO}_{2} \\
(\mathrm{PPM})\end{array}$ \\
\hline $\mathrm{H} / \mathrm{W}=0.65$ & 304 & 35.3 & 1.55 & 5.1 & 353 & 358 \\
$\mathrm{H} / \mathrm{W}=1$ & 304.3 & 34.4 & 1.4 & 5 & 353 & 358 \\
$\mathrm{H} / \mathrm{W}=1.5$ & 305.2 & 34 & 1.34 & 5.1 & 353 & 358 \\
\hline
\end{tabular}

\section{Conclusion}

This paper attempts to quantify and model the effect of street geometry on urban thermal comfort and its weather parameters using computational fluid dynamics technique. A comprehensive comparison of the simulated data demonstrates that;

- The first scenario $(\mathrm{H} / \mathrm{W}=0.65)$ took the lead and achieved the best possible results. Which indicates that a proper street design can enhance the air temperature by $1.2 \mathrm{~K}$, the relative humidity by $1.3 \%$, and the airspeed by $0.21 \mathrm{~m} / \mathrm{s}$ :

- The street canyon geometry has a minor impact on PMV, MRT, $\mathrm{CO}_{2}$ that because of the street canyon geometry is only impact the air flow and its speed. 


\section{Recommendations for further studies}

- Further research is needed to investigate the impact of street canyon geometry on the acoustical and lighting comfort levels in outdoor spaces;

- More study is recommended in different climate zones especially in hot-dry zone;

- Extra investigation is required to quantify the effectiveness of site landform, heat sinks, building adjacency, as well as urban form.

\section{Open Access statement}

This is an open-access article distributed under the terms of the Creative Commons Attribution 4.0 International License (https://creativecommons.org/licenses/by/4.0/), which permits unrestricted use, distribution, and reproduction in any medium, provided the original author and source are credited, a link to the CC License is provided, and changes - if any - are indicated. (SID_1)

\section{References}

[1] Baranyai B., Kistelegdi I. Energy management monitoring and control of public buildings, Pollack Periodica, Vol. 9, No. 2, 2014, pp. 77-79.

[2] Shishegar N. Street design and urban microclimate: Analyzing the effects of street geometry and orientation on airflow and solar access in urban canyons, Journal of Clean Energy Technologies, Vol. 1, No. 1, 2013, pp. 52-54.

[3] Anupriya S. Exploratory study on the relation between urban landscapes and urban corridors for outdoor thermal comfort, Procedia Technology, Vol. 24, 2016, pp. 1801-1807.

[4] Bourbia F., Boucheriba F. (2010). Impact of street design on urban microclimate for semiarid climate (Constantine), Renewable Energy, Vol. 35, No. 2, 2010, pp. 343-344.

[5] Osman M. Evaluating and enhancing design for natural ventilation in walk-up public housing blocks in the Egyptian desert climatic design region, PhD Thesis, University of Dundee, 2011.

[6] Givoni B. Climatic aspects of urban design in tropical regions, Atmospheric Environment, Part B, Urban Atmosphere, Vol. 26, No. 3, 1992, pp. 397-406.

[7] Póth B., Kistelegdi I. The history of the energy and climate concept of the Szentágothai Research Center, Pollack Periodica, Vol. 8, No. 3, 2013, pp. 3-14.

[8] Elgamal N. F. Impact of street design on urban ventilation in hot dry climate using Envimet, Case of Greater Cairo Region, $1^{\text {st }}$ International Conference on Toward a Better Quality of Life, Technische Universität Berlin Campus El Gouna, Egypt, 24-26 November 2017, doi:10.2139/ssrn.3163449.

[9] Széchenyi Square (Pécs), https://en.wikipedia.org/wiki/Sz\%C3\%A9chenyi_square (P\%C3\%A9cs), (last visited 3 September 2018)

[10] Google Earth, Google, earth.google.com. https://www.google.com/maps/place/ Sz\%C3\%A9chenyi $+\mathrm{t} \% \mathrm{C} 3 \% A 9 \mathrm{r} / 46.0766304,18.2276874,191 \mathrm{~m} / \mathrm{data}=! 3 \mathrm{~m} 1 ! 1 \mathrm{e} 3 ! 4 \mathrm{~m} 5 ! 3 \mathrm{~m}$ 4!1s0x4742b103cb90a1cd:0xe4c8f1de02eb8e4f!8m2!3d46.0761668!4d18.2281406, (last visited 27 February 2019).

[11] Energy Design Tools Group, http://energy-design-tools.aud.ucla.edu/climate-consultant/ request-climate-consultant.php, (last visited 25 November 2018). 